but the paper gave rise to an interesting discussion. This dealt principally with a brass rod which had become disintegrated while in use as a floor-bolt in a high-tension electric power station. The bolt passes through the floor inside a procelain tube, and electrical leakage gives rise to the formation of nitric oxides in the air-space of the insulator tube. In the case described by Dr. Stead, and also in a similar one mentioned by Dr. Rosenhain in the discussion, the brass rod either had some minute cracks, due to slight hollow drawing, when first put in, or these were developed while the rod was in service. The nitric acid gases penetrated into these fissures and produced basic salts of zinc and copper which, by their increased volume, widened the cracks and ultimately led to the complete disruption of the rods. An initially sound, annealed brass rod suffers no such damage in the same conditions.

Other interesting papers, by Prof. A. Read and Mr. Greaves, on the influence of nickel on the alloys of aluminium and copper, by $\mathrm{Mr}$. Dewrance on bronze, and by Messrs. Whyte and Desch on the microchemistry of corrosion, were read and fully discussed, the eminently successful meeting only terminating late in the afternoon.

\section{AN EELWORM DISEASE OF RICE.}

$T \mathrm{HE}$ appearance of a rice-disease in eastern Bengal so serious that in certain districts the cultivators were in I9II on the verge of ruin calls for special notice, since rice is, of all important cereals, the one perhaps least subject to serious disease. The matter is dealt with by Dr. E. J. Butler, mycologist to the Agricultural Research Institute at Pusa (Bihar), in a recent pamphlet (Bulletin No. 34, "Diseases of Rice"; Calcutta : Superintendent Government Printing, India, I9I3).

The disease in question (called locally "ufra," from a word meaning "above," owing to a belief that atmospheric conditions are responsible for it) has existed long, but has only recently acquired such an intense form as to call for a special inquiry. From Dr. Butler's researches the active cause appears to be an eelworm, Tylenchus angustus, closely allied to the nematode which causes tulip-root in oats and other cereals. This Bengal worm, however, differs in its mode of attack from the Tylenchus of wheat and oats. It never enters the tissues of the rice-plant, but confines its ravages to epidemic organs wherever these are sufficiently soft and unsilicified to allow the entrance of the "spear" with which its mouth is armed. The inflorescence, the tissue above the nodes, and the growing point, are such weak places, and here the eelworm, both in mature and in larval stages, was abundantly found in all the plants exhibiting " ufra." The results of the attack of such large numbers of Tylenchus are disccloration of the stem and leaves, arrest of the inflorescence, sterility, and mouldiness. The extent of the damage is not accurately known, but in some districts is estimated to amount to half the normal crop.

This "ufra" disease is of a highly infectious quality. The eelworms swim through the submerged paddyfields from one rice-plant to another, which they ascend and attack. Like their allies, these nematodes exhibit great powers of resistance to drought, but little to continued submergence; and hence it is somewhat difficult to account for their abundance in such flooded districts as the rice-growing lands in the Noakhali (eastern Bengal) district. Further investigations are needed on the bionomics of these parasites.

With regard to preventive measures, the only hope- ful indication at present is the behaviour of transplanted rice in contrast to that of broadcast paddy. Dr. Butler shows that the former, though susceptible of attack by inoculation, is not attacked under ordinary conditions, and advocates an extension of the transplanted crop, the improvement of natural drainage, and the more systematic burning of the stubble. The importance of taking adequate prophylactic measures is seen in the geographical position of the infected area. On one side of it is the enormous paddy area of Bengal, on the other the Irrawaddy Delta, which supplies practically the whole of the export rice of India. "A serious disease of rice," says Dr. Butler, "is one of the greatest calamities that could befall the people" in the infected districts, "(where nearly three-quarters of the cultivated area is under paddy), for no other food crop can replace it."

\section{METEOROLOGY IN NETHERLANDS' EAST INDIA. ${ }^{1}$}

THE volume of observations before us contains the hourly readings made at the Batavia Observatory during the year I9Io, which is the forty-fifth year of this uninterrupted series of hourly observations. Investigation of the upper air by balloons and kites has been regularly carried on, and important results were obtained. Several of the registering balloons attained heights exceeding $\mathrm{r}_{5} \mathrm{~km}$. The number of ascents of pilot balloons amounted to 163 ; many were followed by means of theodolites to a height exceeding ro $\mathrm{km}$. The record height reacined was $3 \mathrm{I} \mathrm{km}$. (on September 12, 1912).

The observations at secondary stations include (a) monthly and annual means of air-pressure reduced to the period I866-igri. The influence of the high mountain range of Sumatra is shown in the deffections of the isobars in the direction parallel to the ridge; in the Indian Ocean, to the south-west of the island, there is a relative air-defect in the west monsoon, and an excess of pressure in the east monsoon. Dr. v. Bemmelen (director) also points out that in the west monsoon the isobars show a remarkable curvative over the sea between Borneo and Sumatra. (b) Sunshine observations I909-II: the tables give distinct evidence of the wav the cloudiness increases with height above sea-level, and that insolation is stronger during the east monsoon in East than in West Java. A further discussion of results is postponed until more data are available. (c) Observations of temperature and relative humidity at the agricultural station at Tjipetir, Java, Ig06-II. Owing to deficiency of sunshine in the afternoon, the maximum temperature is shifted towards the morning hours.

With respect to the climate generally, Dr. van Bemmelen remarks that rainfall is the ruling factor in the archipelago, as other meteorological elements are almost constant; the average yearly rainfall at Batavia is a little more than 70 in. The study of changes of weather is of little practical importance, as these are trifling, while a storm-warning service is unnecessary, as cyclones do not pass over the area in question. Although it is at present considered unnecessary to construct daily weather charts, the director thinks it would be of great scientific interest if the conditions could be followed by means of synoptical grouping for either weekly or monthly periods. In connection with this view, mercury barometers have been supplied to several places; it is also proposed to establish meteorological stations on a few of the mountains possessing relief of simple form.

2 (1) Observations made at the Royal Magnetical and Meteorological Observatory, vol, xxxiii. (2) Observations made at Secondary Stations vol. i.

NO. $23 \mathrm{r} 7$, VOL. 93] 